\title{
Study of in-furnace gas-dynamic processes with different design of vortex burners
}

\author{
Oleg M. Koksharev ${ }^{1, *}$, and Andrey V. Gil ${ }^{1}$ \\ ${ }^{1}$ National Research Tomsk Polytechnic University, 634050 Tomsk, Russia
}

\begin{abstract}
The paper considers the combustion chamber of the boiler unit designed for burning Ekibastuz coal by vortex burners with opposed wall firing. Since Ekibastuz coal is not highly reactive, and also has a high content of the mineral part, then vortex burners are used for its combustion. The use of standard two-channel burners leads to increased generation of nitrogen oxides, therefore, in this article the combustion processes of burning Ekibastuz coal using multi-channel burners are considered. The studies were carried out using numerical methods.
\end{abstract}

\section{Introduction}

In the Russian energy sector large boiler units are used mainly flare polyfractional burning of pulverized coal with the application of various types of burners and their layout. The choice of burners and combustion scheme, as well as the type of combustion chamber, is determined by the thermal characteristics of the project fuel from the condition of its rational use.

The specifics of the thermal properties of Ekibastuz coal is a combination of explosion safety, low sulfur content, good flowability and low humidity with high ash content, which is an average of $A^{r}=32,9-41,9 \%$. In this regard, in the boiler unit there are such negative processes as abrasive wear of the heating surfaces, and in the case of a significant change in the content of the mineral part of the fuel, the instability of the combustion process is observed. It is also possible to distinguish a sufficiently high generation of nitrogen oxides, since vortex burner devices are used in the organization of burning of Ekibastuz coal $[1,2]$.

\section{Problem statement}

The open type combustion chamber with solid slag removal and water-walled furnace by $60 \times 5.5 \mathrm{~mm}$ pipes with a step of $64 \mathrm{~mm}$. The side screens at the bottom ash removal form the slopes of the "cold hopper". The ceiling of the furnace is water-walled by tubes of the radiation superheater. The volume of the combustion chamber $\left(1957 \mathrm{~m}^{3}\right)$ is structurally divided into two parts: the upper part in the horizontal section along the axes of the pipes of opposite screens has dimensions of $15744 \times 3776 \mathrm{~mm}$, the lower $-15744 \times 9024 \mathrm{~mm}$ (Fig. 1).

\footnotetext{
* Corresponding author: omk2@tpu.ru
} 
Vortex burners are located at $10800 \mathrm{~mm}$ with an opposite-fired arrangement in one storey of 6 pieces on the side walls of the furnace, with alternating left and right twist of the flow, which provides additional mixing of the adjacent jets of each pair of burners. For the boiler heating oil nozzles of steam spraying are provided, built-in pulverized coal burners. The diameter of the burners on the external secondary air supply channel is $1032 \mathrm{~mm}$, and on the internal air mixture supply channel-530 $\mathrm{mm}$. The diameter of the fuel oil nozzle is $218 \mathrm{~mm}$.

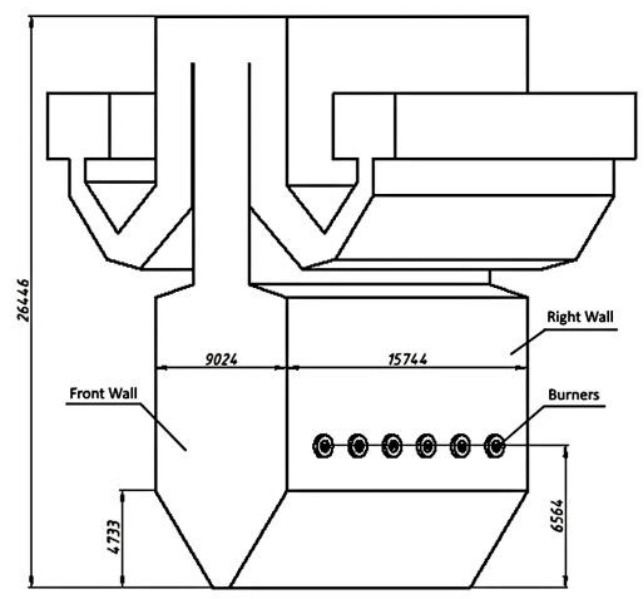

Fig. 1. Geometrical model of the boiler furnace chamber.

For the reconstruction of the boiler was applied a four-channel vortex burners. In the central part there is a fuel oil nozzle with a diameter of $209 \mathrm{~mm}$, then the channel of the dust-air mixture with a diameter of $490 \mathrm{~mm}$ and three channels for supplying secondary air.

During the numerical experiment, the rates of fuel supply and secondary air through the channels were taken to be the same. The axial speed of the fuel-air mixture was $20.0 \mathrm{~m} / \mathrm{s}$, and the secondary air was $25.4 \mathrm{~m} / \mathrm{s}$.

Numerical studies are carried out using Euler-Lagrange approach. Turbulence characteristics are described using the $k-\varepsilon$ standard model. The calculation is carried out by the second order of accuracy. To perform the numerical simulations commercial software ANSYS FLUENT V. 12.1 was used $[3,4]$.

\section{Results and discussion}

Fig. 2 presents the results of numerical simulation of velocities in the horizontal cross section of the combustion chamber in the center of the burners. In both figures, the formation of a vortex swirling flow of burner jets against each burner is observed. Also in the central part of the coaxially spreading swirling streams ejection zone is visible. These results indicate the correctness of the initial and boundary conditions for the combustion of fuels using vortex burners.

On average, the results in both versions are quite similar in absolute values, there are differences in the location of the areas with the minimum speed values.

Analyzing fig. 2 and 3, it can be noted that at the end of the flow of fuel-air mixture and secondary air from the burners with two channels, the mixing intensity is higher than at the end of the flows from the vortex burners with four channels. 


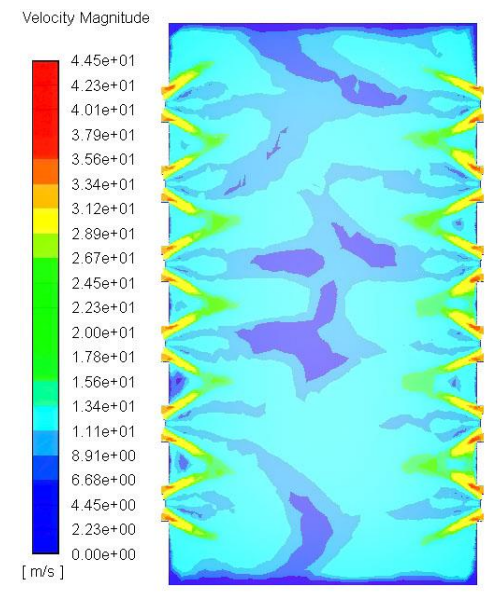

(a)

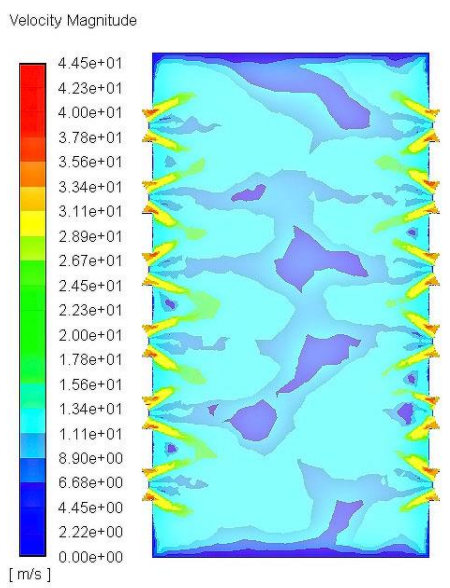

(b)

Fig. 2. Velocity: $a$ - two-channel vortex burners; $b$ - four-channel vortex burners.

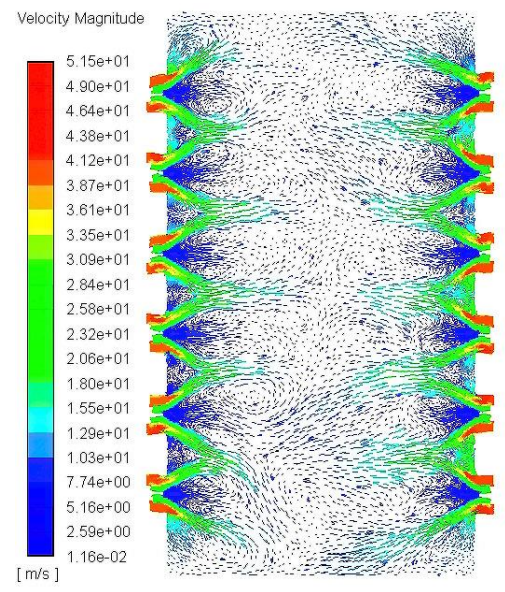

(a)

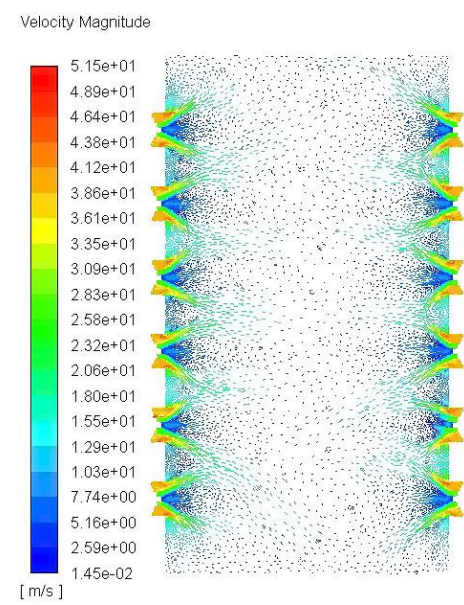

(b)

Fig. 3. Velocity vectors (m/s): a - two-channel vortex burners; b - four-channel vortex burners.

At the specified speeds and the angle of twist of the primary and secondary air, it can be noted that the process of ignition of the fuel occurs in the central part of the swirling burner jets (Fig. 4). The maximum temperature values reach $1700 \mathrm{~K}$ when coal is burned in twochannels burners. When burning coal in four-channel burners the temperature in the horizontal section of the burner devices center is lower and about $1550 \mathrm{~K}$. This fact is associated with the intensity of mixing and oxidation of combustion products with oxygen, respectively. 


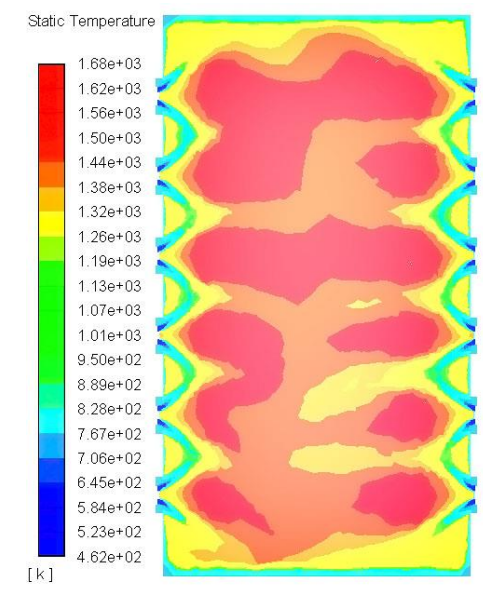

a)

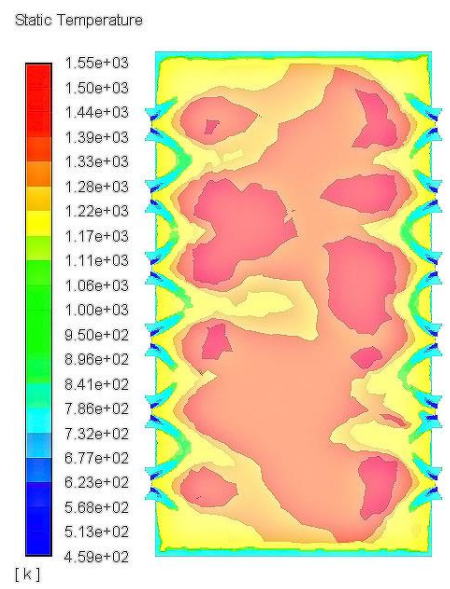

b)

Fig. 4. Flue gas temperature (K): $a$ - two-channel vortex burners; $b$ - four-channel vortex burners.

\section{Conclusions}

This paper presents a numerical study of combustion processes, and in particular the structure of aerodynamic flows and temperature values in the region of flow of burner jets from vortex burners. The numerical simulations performed by commercial software ANSYS FLUENT. The use of such software systems allows to effectively evaluate the alternate methods in the reconstruction or modernization of the boiler units combustion chambers. Based on the results it can be noted that the use of multi-channel burner devices contributes to the reduction of the temperature level in the combustion core and thus contributes to the reduction of the generation of nitrogen oxides.

The studies were carried out with the financial support of the RFBR (project No. 18-3800775_mol_a).

\section{References}

1. A. V. Gil, A. S. Zavorin, A. V. Starchenko, S. V. Obukhov, Power Technology and Engineering 45, 42 (2011)

2. N. V. Vizgavljust, A. V. Starchenko, A. V. Gil, T. S. Taylasheva, Eur.Phys. J.Web Conf. 82, 01040 (2015)

3. P. S. Gergelizhiu, S. A. Khaustov, R. B. Tabakaev, P. Y. Novoseltsev, A. V. Kazakov, A. S. Zavorin, Proc. of 2014 Int. Conf. on Mechanical Engineering, Automation and Control Systems, 109804 (2014)

4. S. A. Khaustov, Y. A. Belousova, K. V.Buvakov, A. Y. Dolgih, R. N. Kulesh, 11th International Forum on Strategic Technology (IFOST - 2016) Proceedings, 2 (2016) 